\title{
Fluorescence spectroscopic characterization of DOM fractions isolated from a filtered river water after ozonation and catalytic ozonation
}

\author{
Tao Zhang ${ }^{\mathrm{a}, \mathrm{b}}$, Jinfeng $\mathrm{Lu}^{\mathrm{a}}$, Jun Ma ${ }^{\mathrm{a}, *}$, Zhimin Qiang ${ }^{\mathrm{b}}$ \\ ${ }^{a}$ School of Municipal and Environmental Engineering, Harbin Institute of Technology, Harbin 150090, China \\ ${ }^{\mathrm{b}}$ Research Center for Eco-Environmental Sciences (RCEES), Chinese Academy of Sciences, Beijing 100085, China
}

Received 1 July 2007; received in revised form 2 November 2007; accepted 2 November 2007

Available online 10 January 2008

\begin{abstract}
Fluorescence spectra were applied to investigate the structural changes of four dominant dissolved natural organic matter (DOM) fractions of a filtered river water before and after ozonation and catalytic ozonation. The ozonation and catalytic ozonation with synthetic goethite $(\mathrm{FeOOH})$ and cerium dioxide $\left(\mathrm{CeO}_{2}\right)$ were carried out under normal conditions, i.e. $\mathrm{pH} 7$, reaction time of $10 \mathrm{~min}$, and ozone/DOC ratio of about 1 . The fluorescence spectra were recorded at both excitation-emission matrix (EEM) and synchronous scanning modes. EEM results reveal that ozonation of these DOM fractions causes a significant decrease of the aromaticity of humic-like structures and an increase of electron withdrawing groups, e.g., carboxylic groups. The catalysts can further improve the destruction of the humic-like structures in catalytic ozonation. Synchronous spectra reveal that ozonation of hydrophobic acid and hydrophilic acid (HIA) yields a significant amount of by-products with low aromaticity and low molecular weight. Catalytic ozonation enhances substantially the formation of these by-products from HIA and improves the destruction of highly polycyclic aromatic structures for all examined DOM fractions.
\end{abstract}

(C) 2007 Published by Elsevier Ltd.

Keywords: Fluorescence; Catalytic ozonation; Natural organic matter; Goethite; Cerium dioxide

\section{Introduction}

Catalytic ozonation with metal oxides is used to improve the ozonation efficiency of recalcitrant organic pollutants in water. It has advantages over other ozonebased advanced oxidation processes (AOPs), such as $\mathrm{O}_{3} /$ $\mathrm{H}_{2} \mathrm{O}_{2}, \mathrm{O}_{3} / \mathrm{UV}$, and $\mathrm{O}_{3} / \mathrm{UV} / \mathrm{H}_{2} \mathrm{O}_{2}$, in terms of not introducing additional energy or chemicals into water (Ma and Graham, 2000). Most of the studies on catalytic ozonation have been focused on removing refractory pollutants (Kasprzyk-Hordern et al., 2003). These pollutants are of trace concentrations in natural surface waters and contribute a

\footnotetext{
* Corresponding author. Tel.: +86 451 86282292; fax: +86 451 82368074

E-mail address: majun@hit.edu.cn (J. Ma).
}

very small portion to dissolved organic carbon (DOC). Dissolved natural organic matter (DOM) dominates in DOC before and after conventional water treatment processes. Moreover, DOM is the precursor of disinfection by-products (DBPs) and the nutrient for bacteria reproduction in water distribution systems (Singer, 1999; Griffini et al., 1999). Therefore, it is very important to investigate the impact of catalytic ozonation on DOM destruction in comparison to ozonation alone. Catalytic ozonation with metal oxides have been found to be able to improve the reduction of DOC and UV absorbance as well as DOM fragmentation for surface waters (Gracia et al., 2000; Park et al., 2004; Lee et al., 2005; Kasprzyk-Hordern et al., 2006). Up to date, however, little research has been conducted on the structural changes of DOM caused by catalytic ozonation. Information on the structural changes 
of DOM is important for interpretation of the influence of catalytic ozonation on DBP formation potential originating from the DOM.

The analytical methods that can be used to characterize natural and oxidized DOM include size-exclusion chromatography, elemental analysis, nuclear magnetic resonance, Fourier-transform infrared spectra, and pyrolysis-GC/ MS. In recent years, fluorescence spectroscopy has been successively used as a simple and sensitive technique to obtain the structural information of aqueous DOM at relatively low concentrations $\left(<20 \mathrm{mg}^{-1}\right.$ TOC) (Mobed et al., 1996; Chen et al., 2003; Świetlik and Sikorska, 2004). It was found reliable in the study of multi-component humic solutes to discern not only DOM from various origins but also DOM subcomponents with varying compositions and functional properties (Coble, 1996; Mobed et al., 1996; McKnight et al., 2001; Baker, 2002; Chen et al., 2003; Liu et al., 2007). The position, shift, and intensity of fluorescence peaks can be correlated to structural information such as polycondensation, aromaticity, and the content of functional electron-donating/withdrawing groups (Chen et al., 2003). With respect to investigating oxidation-induced structural changes of DOM, the fluorescence was used to examine the structural changes of DOM before and after chlorination, ozonation, $\mathrm{ClO}_{2}$ oxidation, and photocatalytic oxidation (Korshin et al., 1999; Win et al., 2000; Świetlik and Sikorska, 2004; Uyguner and Bekbolet, 2005).

To well understand the performances of catalytic ozonation in water treatment, its impact on DOM structural composition needs to be carried out. The main purpose of this study was to reveal the impact of catalytic ozonation on the structural composition of individual DOM fractions by means of fluorescence spectroscopy. Goethite $(\mathrm{FeOOH})$ and cerium dioxide $\left(\mathrm{CeO}_{2}\right)$ were selected as catalysts, because they are active in the degradation of both DOM and trace organic pollutants during catalytic ozonation (Park et al., 2004; Zhang et al., 2005). Moreover, the dissolution of the catalysts into water is negligible as their solubility product constants are as low as $3 \times 10^{-39}$ and $4 \times 10^{-51}$, respectively. Because the released metal ions in water are extremely low in concentrations, they exert nearly no impact on the fluorescence intensity of the DOM fractions.

\section{Experimental}

\subsection{Catalysts preparation and characterization}

FeOOH was synthesized following a method described by Kandori et al. (1991). It was a process of precipitation of ferric nitrate with sodium hydroxide followed by aging the precipitate at $\mathrm{pH}>12$ for more than $48 \mathrm{~h}$. Then, alkaline was removed from the precipitate by repeated rinses with boiled Milli-Q water until the $\mathrm{pH}$ of the rinsing water remained constant. The precipitate was finally dried at $120^{\circ} \mathrm{C}$ for $24 \mathrm{~h}$. It was confirmed to be pure goethite with
Table 1

Major characteristics of the catalysts

\begin{tabular}{lllll}
\hline Catalyst & $\mathrm{pH}_{\mathrm{zpc}}$ & $\begin{array}{l}\text { Surface OH density } \\
\left(\mathrm{mmol} \mathrm{g}^{-1}\right)\end{array}$ & $\begin{array}{l}\text { BET specific surface } \\
\text { area }\left(\mathrm{m}^{2} \mathrm{~g}^{-1}\right)\end{array}$ & $\begin{array}{l}\text { Average pore } \\
\text { size }(\mathrm{nm})\end{array}$ \\
\hline $\mathrm{FeOOH}$ & 7.0 & 0.5 & 68.4 & 24 \\
$\mathrm{CeO}_{2}$ & 6.6 & 0.4 & 117 & 7.9 \\
\hline
\end{tabular}

X-ray diffractometer. Cerium nitrate was calcined at $480{ }^{\circ} \mathrm{C}$ for $2 \mathrm{~h}$ to prepare $\mathrm{CeO}_{2}$. The catalyst particles with a diameter range of $0.075-0.3 \mathrm{~mm}$ were used in the experiments.

The characteristics of the catalysts are summarized in Table 1. The BET surface area, pore volume, and average pore size of the catalysts were obtained on a surface area and porosity analyzer (ASAP 2020, Micromeritics). The density of surface hydroxyl groups on the catalysts in water was measured according to a saturated deprotonation method (Laiti et al., 1995). The $\mathrm{pH}_{\mathrm{zpc}}(\mathrm{pH}$ of zero point of surface charge) was measured with a powder addition method (Newcombe et al., 1993). Another method proposed by Stumm (1992) was also employed to measure the $\mathrm{pH}_{\mathrm{zpc}}$ for the purpose of comparison. Same $\mathrm{pH}_{\mathrm{zpc}}$ values were obtained using the two methods.

\subsection{DOM isolation and fractionation}

Because catalytic ozonation is generally used following filtration, DOM in a filtered river water was used in the experiments. The source water from Songhua River at the upstream of Harbin city was pretreated successively with aluminum sulfate coagulation, sand filtration, and membrane filtration with molecular size cut-off of $50 \mathrm{kDa}$ in a water treatment plant, in which process the DOC of the water was reduced from $4.34 \mathrm{mg}^{-1}$ to $3.31 \mathrm{mg}^{-1}$. 5001 of the pretreated water was used for DOM isolation and fractionation, following a procedure described by Leenheer (1981) and Świetlik et al. (2004) with minor modifications. The water was pumped consecutively through $500 \mathrm{ml}$ XAD- 8 and $300 \mathrm{ml}$ XAD-4 Amberlite resins at a flow rate of $60 \mathrm{ml} \mathrm{min}^{-1}$. Hydrophobic base (HOB) was eluted from XAD-8 with $400 \mathrm{ml}$ of $0.1 \mathrm{M} \mathrm{HCl}$ and $400 \mathrm{ml}$ of $0.01 \mathrm{M} \mathrm{HCl}$ in sequence at a flow rate of $20 \mathrm{ml} \mathrm{min}{ }^{-1}$. The effluent from XAD-8/XAD-4 was adjusted to $\mathrm{pH} 2$ with concentrated $\mathrm{HCl}$ and consecutively passed through the two resins again. Process was controlled by DOC measurement in the effluent and was discontinued when DOC concentration exceeded $1 \mathrm{mg} 1^{-1}$. After rinsing the XAD-8 with $400 \mathrm{ml}$ of $0.01 \mathrm{M} \mathrm{HCl}$ and $400 \mathrm{ml}$ of distilled water at $20 \mathrm{ml} \mathrm{min}^{-1}$, hydrophobic acid (HOA) was eluted from the resin with 1.01 of $0.1 \mathrm{M} \mathrm{NaOH}$ and 0.51 of distilled water at the same flow rate. Then, the XAD- 8 resin was dried at $50{ }^{\circ} \mathrm{C}$ for $24 \mathrm{~h}$ before being Soxhlet-extracted with methanol. Hydrophobic neutral (HON) was eluted from the resin with methanol. Methanol was removed from the extract by vacuum evaporation at $60{ }^{\circ} \mathrm{C}$ to obtain the dried HON. The mixture of hydrophilic fractions were desorbed from the XAD-4 resin by sequen- 
tial elutions with 1.01 of $0.1 \mathrm{M} \mathrm{NaOH}$ and $500 \mathrm{ml}$ of distilled water at $20 \mathrm{ml} \mathrm{min}{ }^{-1}$. Then, the mixed eluate was acidified to $\mathrm{pH} 2$ with concentrated $\mathrm{HCl}$ and passed through $300 \mathrm{ml}$ of AG-MP-50 resin and $300 \mathrm{ml}$ of Duolite A-7 resin consecutively. To ensure sufficient adsorption, the effluent was circulated through the columns of the above two resins, respectively at a gravity flow rate of $20 \mathrm{ml} \mathrm{min}{ }^{-1}$ for five times. The final effluent was collected as hydrophilic neutral (HIN). Hydrophilic base (HIB) was retained on the cation-exchange resin, AG-MP-50, and hydrophilic acid (HIA) was adsorbed on the anionexchange resin, Duolite A-7. HIB was eluted from AGMP-50 with $500 \mathrm{ml}$ of $1.0 \mathrm{M} \mathrm{NH}_{4} \mathrm{OH}$ at $20 \mathrm{ml} \mathrm{min}^{-1}$, while HIA was eluted from Duolite A-7 by $500 \mathrm{ml}$ of $3.0 \mathrm{M}$ $\mathrm{NH}_{4} \mathrm{OH}$. These DOM fractions except $\mathrm{HON}$ were all dried with vacuum evaporation at $40^{\circ} \mathrm{C}$.

The isolated DOM fractions accounted for $80 \%$ of the total DOC of the filtered river water. Table 2 shows the proportions of the individual DOM fractions to total DOC of the isolated DOM and their molecular weight ranges. The percentages of $\mathrm{HOB}$ and hydrophilic fractions are quite low, which is similar to that reported by Świetlik et al. (2004) for a filtered water. However, the HON content of the water is quite high compared to that reported by other researchers such as Świetlik et al. (2004) and Korshin et al. (1997). Since the percentages of DOM fractions of different water sources (such as water type and climate zone) varied significantly (Leenheer, 1981; Korshin et al., 1997), this difference is probably ascribed to different waters used for DOM isolation and fractionation. On the basis of their relative abundance in the isolated DOM, hydrophobic acid and neutral (HOA and HON) and hydrophilic acid and base (HIA and HIB), were used in this study.

\subsection{Experimental procedure}

The individual DOM fractions were dissolved in Milli-Q water, respectively at DOC concentration of about $10 \mathrm{mg}^{-1}$ DOC. These model DOM fraction solutions were adjusted to $\mathrm{pH} 7.0$ with $2 \%(\mathrm{w} / \mathrm{w}) \mathrm{NaOH}$ and $\mathrm{HClO}_{4}$. Milli-Q water cooled with circulated water of $16^{\circ} \mathrm{C}$ was continuously bubbled with gaseous ozone produced with an ozone generator (Tongli XFZ-58I, Tsinghua). The aqueous ozone concentration was detected continuously with ultraviolet spectrometer at $\lambda=258 \mathrm{~nm} \quad(\varepsilon=3000$

Table 2

Distribution and molecular weight of the isolated DOM fractions

\begin{tabular}{lll}
\hline Fraction & $\begin{array}{l}\text { Percentage to total isolated DOM } \\
(\%)\end{array}$ & $\begin{array}{l}\text { Molecular weight range } \\
(\mathrm{Da})\end{array}$ \\
\hline HOA & 49.6 & $700-4000$ \\
HON & 46.1 & $700-3000$ \\
HOB & 0.4 & $700-3000$ \\
HIA & 2.5 & $600-3000$ \\
HIN & 0.2 & $600-3000$ \\
HIB & 1.2 & $600-3000$ \\
\hline
\end{tabular}

$\mathrm{M}^{-1} \mathrm{~cm}^{-1}$ ) until it reached a steady state. The ozone-bearing water $\left(20 \mathrm{ml}, 10.0 \mathrm{mg} \mathrm{l}^{-1}\right)$ was quickly mixed with $20 \mathrm{ml}$ of the model DOM fraction solution in a glass reactor, thus getting an initial aqueous ozone/DOC ratio of about 1 . In the case of catalytic ozonation, the catalyst was also instantly introduced into the reaction solution with a dosage of $100 \mathrm{mg}^{-1}$. Then, the reactor was sealed and magnetically stirred in a chamber being cooled with circulated water of $18^{\circ} \mathrm{C}$. The reaction was allowed to proceed for $10 \mathrm{~min}$ which is a conventional ozonation time used for pollutants destruction in water treatment plants. Thereafter, the reaction solution was bubbled with nitrogen gas to blow out unreacted ozone into $2 \%$ KI solution. Experiments of catalyst-adsorption of the individual DOM fractions were carried out at the same conditions, except that the same volume of Milli-Q water was used instead of the ozone-bearing water. All samples were filtered through $0.45 \mu \mathrm{m}$ acetate fiber filters. The reaction solution was not buffered, because it was noted that its $\mathrm{pH}$ decrease was less than 0.3 during the course of reaction for either ozonation or catalytic ozonation experiments.

\subsection{Analysis}

Fluorescence was measured in a $1-\mathrm{cm}$ cuvette using a Jasco FP-6500 spectrofluorometer at ambient temperature of $24^{\circ} \mathrm{C}$. Each excitation-emission matrix (EEM) was generated by scanning excitation wavelengths from 240 to $400 \mathrm{~nm}$ with $5 \mathrm{~nm}$ steps, and detecting the emitted fluorescence between 300 and $500 \mathrm{~nm}$ with $2 \mathrm{~nm}$ steps. The scanning speed was $5000 \mathrm{~nm} \mathrm{~min}^{-1}$. The equipment was auto-zeroed prior to each analysis. Raman signal of water (excitation at $348 \mathrm{~nm}$, emission at $395-400 \mathrm{~nm}$ ) was also measured as a quality control for daily analysis. Synchronous fluorescence spectra (SF) were collected with constant offsets of 21, 32, 44, 66, and $77 \mathrm{~nm}$ between excitation and emission wavelengths as proposed by Świetlik and Sikorska (2004). The excitation wavelengths in SF increased from 240 to $700 \mathrm{~nm}$. The SF spectra were smoothed with a Savitzky-Golay filter afterwards. Fluorescence intensity variation in triplicate experiments was less than $5 \%$.

DOC was measured on a TOC analyzer (Model 3100, Jena) with analytical variance of $\pm 0.01 \mathrm{mg}^{-1} \quad(n=3)$. UV absorbance was measured with a spectrophotometer (UV-2550, Shimadzu) with analytical variance of \pm 0.001 $(n=3)$. High-pressure size exclusion chromatography (HP-SEC) was used to characterize the molecular weight distribution of the original DOM fractions. The equipment included a gel column (Ultrahydrogel ${ }^{\mathrm{TM}} 250,7.8 \times 300 \mathrm{~mm}$, Waters), a binary pump (Model 1525, Waters), and a UV detector (Model 2487, Waters). The eluent was buffered with $0.01 \mathrm{M}$ phosphate to $\mathrm{pH}$ 7.0. Operation conditions were as follows: eluent flow rate $0.4 \mathrm{ml} \mathrm{min}^{-1}$, injection volume $200 \mu \mathrm{l}$, UV detector wavelength $254 \mathrm{~nm}$, retention time $33 \mathrm{~min}$. According to Her et al. (2003), calibration for molecular weight as a function of retention time $(t)$ 
(expressed as $\log _{10} \mathrm{MW}=11.556-0.4563 \mathrm{t}, R^{2}=0.991$ ) was set up with polyethylene glycols (i.e., 20, 10, 6, 1, and $0.6 \mathrm{kDa}$ ) and salicylic acid as standards.

\section{Results and discussion}

\subsection{Activity of catalysts in improving ozonation of DOM}

Table 3 shows DOC and $\mathrm{UV}_{254}$ of the four individual DOM fractions before and after ozonation, catalytic ozonation, and catalyst-adsorption. Results indicate that ozonation is relatively ineffective in the mineralization of these fractions. However, it is quite effective in the destruction of aromatic and double bond systems as indicated by $\mathrm{UV}_{254}$. Under the experimental condition, $\mathrm{O}_{3} / \mathrm{FeOOH}$ oxidation shows higher DOC removal for the fractions except HOA than ozonation, and improves $\mathrm{UV}_{254}$ reduction for all the fractions examined. $\mathrm{O}_{3} / \mathrm{CeO}_{2}$ oxidation achieves higher DOC and $\mathrm{UV}_{254}$ removal than $\mathrm{O}_{3} / \mathrm{FeOOH}$. The high efficiency of $\mathrm{CeO}_{2}$ in catalytic ozonation is associated with its higher sorption for these fractions. It is noted that the removal of DOC and $U^{254}$ in catalytic ozonation is higher than the combined removal in ozonation and catalyst-adsorption for most of these fractions, indicating the catalysts are active in improving the ozonation of DOM.

\subsection{Structural changes examined by EEM}

The EEM spectra of the DOM fractions before and after ozonation, catalytic ozonation, and adsorption by the catalysts are shown in Fig. 1. Two apparent EEM peaks, exhibiting the peak maxima at ex/em of $240-260 / 420$ $450 \mathrm{~nm}$ and $290-330 / 400-440 \mathrm{~nm}$, were observed for all the original DOM fractions. The two peaks correspond to humic-like structures that are classified as Type A (at ex/em: 260/450 nm) and Type C (at ex/em: 330/450 nm) (Coble, 1996). The EEM spectra also show Rayleigh and Raman scattering peaks originating from an interaction between the excitation light and water molecules. The Rayleigh and second-order Rayleigh scattering peaks occur at the same wavelength and twice the wavelength of the excitation light, respectively. Raman scatter induces a shift to longer wavelengths.

The intensities and positions of the EEM peaks before and after ozonation, catalytic ozonation, and adsorption by the catalysts are summarized in Table 4 . Results show that ozonation decreases the intensities of Type $\mathrm{A}$ and Type $\mathrm{C}$ fluorophores by about $50-70 \%$ for all examined DOM fractions. According to Uyguner and Bekbolet (2005), the intensity decrease indicates the depletion of aromatic structures and the increment of electron withdrawing groups in aromatic compounds. $\mathrm{FeOOH}$ sorption only slightly reduces the intensity of Type A and Type C fluorophores of the DOM fractions, indicating that the adsorption of the fluorophores on $\mathrm{FeOOH}$ was insignificant. In contrast, $\mathrm{CeO}_{2}$ shows much higher sorption ability for these fluorophores. Because of the hydrophilic nature of metal oxides in water, the adsorption of DOM is mainly due to surface coordination between the surface metal sites and DOM functionalities, such as carboxylic and phenolic groups (Yost et al., 1990). According to Tombácz et al. (2004), the quantity of hydroxyl groups generally repre-

Table 3

DOC and $\mathrm{UV}_{254}$ of individual DOM fractions before and after ozonation, catalytic ozonation, and catalyst-adsorption

\begin{tabular}{|c|c|c|c|c|}
\hline Sample & $\mathrm{DOC}\left(\mathrm{mg}^{-1}\right)$ & DOC reduced $(\%)$ & $\mathrm{UV}_{254}$ & $\mathrm{UV}_{254}$ reduced $(\%)$ \\
\hline HOA & 4.80 & & 0.132 & \\
\hline $\mathrm{HOA} / \mathrm{O}_{3}$ & $4.55 \pm 0.11$ & $5.2 \pm 2.2$ & $0.073 \pm 0.002$ & $44.7 \pm 1.5$ \\
\hline $\mathrm{HOA} / \mathrm{O}_{3} / \mathrm{FeOOH}$ & $4.70 \pm 0.05$ & $2.1 \pm 1.0$ & $0.070 \pm 0.001$ & $47.0 \pm 0.8$ \\
\hline $\mathrm{HOA} / \mathrm{O}_{3} / \mathrm{CeO}_{2}$ & $3.32 \pm 0.07$ & $30.8 \pm 1.4$ & $0.060 \pm 0.002$ & $54.5 \pm 1.5$ \\
\hline $\mathrm{HOA} / \mathrm{CeO}_{2}$ & $4.27 \pm 0.03$ & $11.0 \pm 0.6$ & $0.127 \pm 0.001$ & $3.8 \pm 0.8$ \\
\hline $\mathrm{HON}$ & 5.10 & & 0.065 & \\
\hline $\mathrm{HON} / \mathrm{FeOOH}$ & $4.48 \pm 0.04$ & $12.2 \pm 0.8$ & $0.062 \pm 0.001$ & $4.6 \pm 1.5$ \\
\hline $\mathrm{HON} / \mathrm{O}_{3} / \mathrm{CeO}_{2}$ & $3.99 \pm 0.05$ & $21.8 \pm 1.0$ & $0.011 \pm 0.001$ & $83.1 \pm 1.5$ \\
\hline $\mathrm{HON} / \mathrm{CeO}_{2}$ & $4.46 \pm 0.03$ & $12.5 \pm 0.6$ & $0.057 \pm 0.001$ & $12.3 \pm 1.5$ \\
\hline HIA & 4.72 & & 0.077 & \\
\hline $\mathrm{HIA} / \mathrm{O}_{3}$ & $4.58 \pm 0.07$ & $3.0 \pm 1.4$ & $0.047 \pm 0.001$ & $39.0 \pm 1.3$ \\
\hline $\mathrm{HIA} / \mathrm{O}_{3} / \mathrm{FeOOH}$ & $3.54 \pm 0.09$ & $25.0 \pm 2.0$ & $0.043 \pm 0.002$ & $44.2 \pm 2.6$ \\
\hline $\mathrm{HIB} / \mathrm{O}_{3}$ & $4.60 \pm 0.08$ & $6.5 \pm 1.6$ & $0.062 \pm 0.001$ & $41.0 \pm 1.0$ \\
\hline $\mathrm{HIB} / \mathrm{O}_{3} / \mathrm{FeOOH}$ & $3.40 \pm 0.06$ & $30.9 \pm 1.2$ & $0.046 \pm 0.002$ & $56.2 \pm 1.9$ \\
\hline $\mathrm{HIB} / \mathrm{FeOOH}$ & $4.64 \pm 0.03$ & $5.7 \pm 0.6$ & $0.101 \pm 0.001$ & $3.8 \pm 1.0$ \\
\hline $\mathrm{HIB} / \mathrm{O}_{3} / \mathrm{CeO}_{2}$ & $2.57 \pm 0.04$ & $47.8 \pm 0.8$ & $0.033 \pm 0.001$ & $68.6 \pm 1.0$ \\
\hline $\mathrm{HIB} / \mathrm{CeO}_{2}$ & $3.57 \pm 0.04$ & $27.4 \pm 0.8$ & $0.079 \pm 0.001$ & $24.8 \pm 1.0$ \\
\hline
\end{tabular}





Fig. 1. EEM spectra of the DOM fractions before and after ozonation, catalytic ozonation, and catalyst-adsorption: (a) HOA; (b) HON; (c) HIA; and (d) HIB.

sents the amount of surface coordination sites on metal oxides in water. However, the surface hydroxyl density of $\mathrm{CeO}_{2}$ is lower than that of $\mathrm{FeOOH}$ (see Table 1). Therefore, as we suggested in a former study (Zhang et al., 2005), the higher sorption ability of $\mathrm{CeO}_{2}$ is more likely to be related with the much stronger affinity of surface $\mathrm{Ce}(\mathrm{IV})$ sites for the coordination functionalities of DOM molecules. Catalytic ozonation with $\mathrm{FeOOH}$ decreases the intensities of Type A and Type C fluorophores of the DOM fractions by about $22-53 \%$ compared to ozonation alone. The improvement by $\mathrm{O}_{3} / \mathrm{FeOOH}$ obviously cannot be attributed only to the adsorption of DOM by $\mathrm{FeOOH}$, as it is very weak. The activity of $\mathrm{FeOOH}$ is possibly due to its ability in promoting hydroxyl radical generation from aqueous ozone, which has been reported previously (Lim et al., 2001). $\mathrm{O}_{3} / \mathrm{CeO}_{2}$ oxidation decreases 

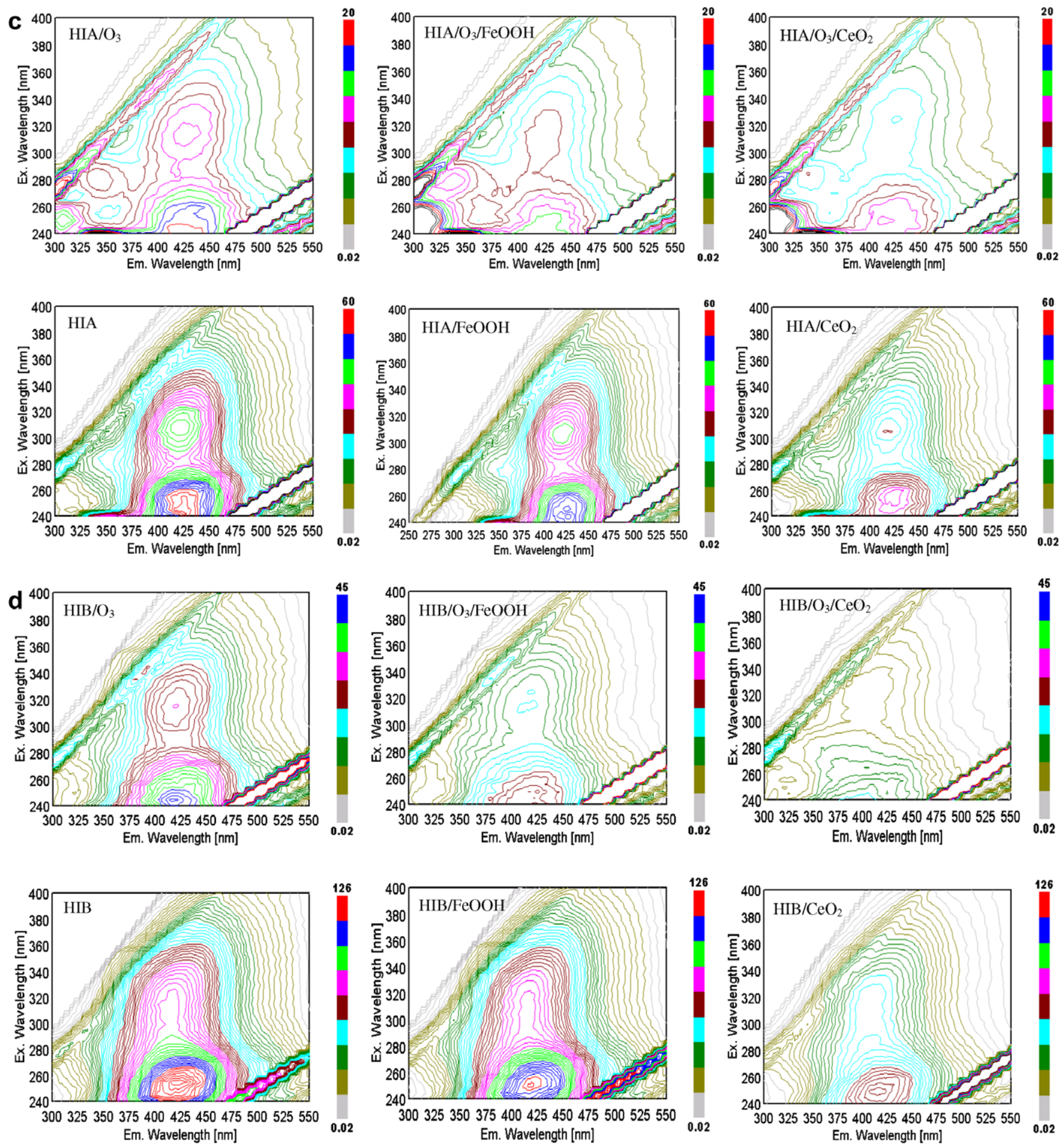

Fig. 1 (continued)

the intensities of Type A and Type C fluorophores of the DOM fractions by about $30-100 \%$ compared to ozonation alone. The higher intensity reduction by $\mathrm{O}_{3} / \mathrm{CeO}_{2}$ than that by $\mathrm{O}_{3} / \mathrm{FeOOH}$ possibly has relationship with the relativelystronger affinity of the fluorophores to $\mathrm{CeO}_{2}$ than to $\mathrm{FeOOH}$.

Despite the intensity reduction of the fluorophores, ozonation also causes peak-shift for some DOM fractions.
Ozonation shifts the maximum excitation wavelengths of Type A fluorophores of HOA, HON, and HIB to shorter wavelengths. According to former researches (Coble, 1996; Świetlik and Sikorska, 2004), the blue-shift indicates following ozone-induced changes for the Type A fluorophores of these DOM fractions: (1) the decomposition of condensed aromatic moieties to smaller molecules; (2) the reduction in the degree of $\pi$-electron systems, such as 
Table 4

Intensities and positions of the EEM peak maxima before and after ozonation, catalytic ozonation, and adsorption by the catalysts

\begin{tabular}{|c|c|c|c|c|c|c|c|c|}
\hline \multirow[t]{2}{*}{ Fraction } & \multicolumn{2}{|l|}{ Type A } & \multicolumn{2}{|l|}{ Type C } & \multicolumn{2}{|l|}{$\underline{\text { Protein-like I }}$} & \multicolumn{2}{|l|}{ Protein-like II } \\
\hline & Position, ex/em(nm/nm) & Int. $^{\text {a }}$ (a.u.) & Position, ex/em (nm/nm) & Int. a (a.u.) & Position, ex/em (nm/nm) & Int. $^{\text {a }}$ (a.u.) & Position, ex/em (nm/nm) & Int. $^{\text {a }}$ (a.u.) \\
\hline HOA & $255-265 / 430-445$ & 108.8 & $300-315 / 420-430$ & 69.7 & - & - & - & - \\
\hline $\mathrm{HOA} / \mathrm{Cl}$ & $255-265 / 430-445$ & 103.9 & $300-315 / 420-430$ & 66.0 & - & - & - & - \\
\hline $\mathrm{HOA} / \mathrm{C} 2$ & $255-265 / 430-445$ & 79.4 & $300-315 / 420-430$ & 44.0 & - & - & - & - \\
\hline $\mathrm{HOA} / \mathrm{O}$ & $250-255 / 430-445$ & 45.6 & $310-320 / 425-435$ & 30.0 & $250-255 / 305-320$ & 27.8 & $280-288 / 330-345$ & 23.3 \\
\hline $\mathrm{HOA} / \mathrm{O} / \mathrm{Cl}$ & $250-255 / 422-445$ & 35.6 & $310-320 / 425-440$ & 23.3 & $250-255 / 305-320$ & 24.4 & $280-288 / 330-345$ & 21.1 \\
\hline $\mathrm{HOA} / \mathrm{O} / \mathrm{C} 2$ & $255-260 / 422-445$ & 30.0 & $290-300 / 425-435$ & 18.9 & $250-255 / 305-320$ & 22.2 & $280-288 / 335-350$ & 15.6 \\
\hline $\mathrm{HON}$ & $255-260 / 425-440$ & 45.6 & $285-300 / 405-430$ & 27.8 & - & - & - & - \\
\hline $\mathrm{HON} / \mathrm{Cl}$ & $255-260 / 425-440$ & 41.1 & $285-290 / 405-430$ & 25.6 & - & - & - & - \\
\hline $\mathrm{HON} / \mathrm{C} 2$ & $250-258 / 425-440$ & 20.0 & $300-320 / 405-450$ & 11.1 & - & - & - & - \\
\hline $\mathrm{HON} / \mathrm{O}$ & $240-255 / 410-435$ & 16.9 & $298-318 / 400-430$ & 11.3 & - & - & - & - \\
\hline $\mathrm{HON} / \mathrm{O} / \mathrm{C} 1$ & $240-250 / 370-435$ & 7.9 & $290-318 / 400-430$ & 5.6 & - & - & - & - \\
\hline $\mathrm{HON} / \mathrm{O} / \mathrm{C} 2$ & - & - & - & - & - & - & - & - \\
\hline HIA & $240-258 / 420-430$ & 56.7 & $300-315 / 420-430$ & 44.4 & - & - & - & - \\
\hline $\mathrm{HIA} / \mathrm{Cl}$ & $240-258 / 420-430$ & 53.3 & $300-315 / 420-430$ & 41.1 & - & - & - & - \\
\hline HIA/C2 & $250-260 / 420-430$ & 37.8 & $300-315 / 420-430$ & 27.8 & - & - & - & - \\
\hline HIA/O & $240-250 / 410-440$ & 18.9 & $305-320 / 420-430$ & 13.3 & $250-255 / 300-320$ & 15.6 & $270-285 / 330-350$ & 11.1 \\
\hline $\mathrm{HIA} / \mathrm{O} / \mathrm{C} 1$ & $240-258 / 400-440$ & 14.4 & $305-330 / 420-430$ & 10.0 & $250-255 / 300-320$ & 22.2 & $270-285 / 330-350$ & 13.3 \\
\hline $\mathrm{HIA} / \mathrm{O} / \mathrm{C} 2$ & $248-255 / 410-425$ & 13.3 & $325-330 / 425-435$ & 8.9 & $250-255 / 300-320$ & 22.2 & $280-285 / 335-345$ & 10.0 \\
\hline HIB & $255-260 / 420-430$ & 126.0 & $300-328 / 405-430$ & 84.0 & - & - & - & - \\
\hline $\mathrm{HIB} / \mathrm{C} 1$ & $253-258 / 420-430$ & 116.0 & $300-325 / 405-430$ & 78.0 & - & - & - & - \\
\hline $\mathrm{HIB} / \mathrm{C} 2$ & $248-255 / 405-425$ & 68.0 & $300-330 / 400-430$ & 46.0 & - & - & - & - \\
\hline HIB/O & $240-250 / 415-425$ & 43.9 & $310-320 / 420-425$ & 29.2 & - & - & - & - \\
\hline $\mathrm{HIB} / \mathrm{O} / \mathrm{Cl}$ & $240-255 / 400-425$ & 27.0 & $310-320 / 410-425$ & 18.0 & - & - & - & - \\
\hline $\mathrm{HIB} / \mathrm{O} / \mathrm{C} 2$ & $240-248 / 375-415$ & 18.0 & $300-335 / 390-420$ & 10.1 & - & - & - & - \\
\hline
\end{tabular}

$\mathrm{C} 1$ : synthetic $\mathrm{FeOOH} ; \mathrm{C} 2: \mathrm{CeO}_{2}$; O: ozonation.

${ }^{\mathrm{a}}$ Int., intensity. 
decreasing the number of aromatic rings or conjugated bonds in a chain structure; and (3) the elimination of certain functional groups such as carbonyl, hydroxyl, and amine. Ozonation also shifts Type $\mathrm{C}$ fluorophores of HOA, HON, and HIA in excitation wavelength to longer wavelengths. The red-shift is ascribed to the increase of carbonyl, hydroxyl, alkoxyl, amino, and carboxyl groups in the structures of the fluorophores (Chen et al., 2003; Świetlik and Sikorska, 2004; Uyguner and Bekbolet, 2005).

In comparison to ozonation, catalytic ozonation shifts further the peak maxima of some of the examined DOM fractions. $\mathrm{O}_{3} / \mathrm{FeOOH}$ expands the EEM peak of Type A fluorophores of all examined fractions to shorter emission wavelengths. $\mathrm{O}_{3} / \mathrm{CeO}_{2}$ blue-shifts significantly the emission wavelengths of Type A fluorophores of HIB. The results indicate again that catalytic ozonation can improve the destruction of Type A humic-like structures. As Type C fluorophores are concerned, the maximum excitation wavelengths of HIA and HOA are found red- and blue-shifted after $\mathrm{O}_{3} / \mathrm{CeO}_{2}$ oxidation, respectively. According to former researches (Świetlik and Sikorska, 2004; Uyguner and Bekbolet, 2005), the results indicate that $\mathrm{O}_{3} / \mathrm{CeO}_{2}$ can enhance the oxidation of Type $\mathrm{C}$ fluorophores of HIA producing more carbonyl, hydroxyl, and, alkoxyl groups, and improve the decomposition and/or destruction of C fluorophores of HOA.

The EEM spectra also reveal the emergence of two new EEM peaks after ozonation at the ex/em of 240-260/300 $320 \mathrm{~nm}$ and 270-290/330-350 nm for HOA and HIA (see Fig. 1). These peaks represent aromatic amino acids, either free or as protein constituents, which have been described as tyrosine-like (ex/em 240-260/300-320 nm) and tryptophan-like (ex/em 270-290/330-350 nm) by other researchers (Coble, 1996; Elliott et al., 2006; Liu et al., 2007). The results indicate that ozonation of HOA and HIA leads to the emergence of a significant amount of aromatic amino acid functionalities. As described by Świetlik and Sikorska (2004), the appearance of the protein-like fluorophores can be attributed to the break down of high-molecule proteinaceous materials by ozonation, which exposes small-molecule amino functionalities. Catalytic ozonation causes no apparent shift for the new peaks. However, the intensities of these peaks after catalytic ozonation are different from those after ozonation alone under the experimental conditions (see Table 4). The intensity of the protein-like fluorophores of HOA is lower after $\mathrm{O}_{3} / \mathrm{FeOOH}$ oxidation and especially after $\mathrm{O}_{3} / \mathrm{CeO}_{2}$ oxidation than that after ozonation alone. The catalytic ozonation may further oxidize the low-molecule aromatic amino functionalities produced from HOA to other byproducts. The impact of catalytic ozonation on the protein-like fluorophores of HIA depends on the catalyst type. $\mathrm{O}_{3} / \mathrm{FeOOH}$ oxidation enriches the formation of protein-like fluorophores. $\mathrm{O}_{3} / \mathrm{CeO}_{2}$ oxidation promotes the formation of tyrosine-like functionalities, but slightly inhibits the formation of tryptophan-like functionalities.

\subsection{Structural changes examined by synchronous spectra}

The EEM spectra contain complete fingerprints of DOM. However, it is quite difficult to clearly interpret the potential information contained in the EEM spectra (Cabaniss, 1992). SF spectra, therefore, were used to explore additional structure information with improved peak resolution for DOM (Cabaniss, 1992; Chen et al., 2003; Świetlik and Sikorska, 2004).

The shape, bandwidth, and peak position of a SF spectrum change with the increased offset $(\Delta \lambda)$ between excitation and emission wavelengths (Alberts and Takács, 2004; Sierra et al., 2005). The selectivity of SF toward any given component in a mixture can be enhanced by using a $\Delta \lambda$ that corresponds to the wavelength interval between the excitation and the emission maxima for that component (Vo-Dinh, 1978). However, such an ideal $\Delta \lambda$ interval seems impossible for the mixture of humic fluorophores. Several $\Delta \lambda \mathrm{s}$, therefore, should be tested to have a better picture of DOM samples. Most studies employed a $\Delta \lambda$ value of 18 or $20 \mathrm{~nm}$ (Cabaniss, 1992; Peuravuori et al., 2002). It was recently reported that a higher $\Delta \lambda$ value would be better to register and distinguish the fluorophores of DOM at low concentrations, such as less than $5 \mathrm{mg}^{-1}$ TOC (Świetlik and Sikorska, 2004; Sierra et al., 2005).

The wavelength offset of $\Delta \lambda=66 \mathrm{~nm}$ was found optimal for the DOM SF spectra here, because more peaks were displayed in this case. All of the original DOM fractions exhibit four characteristic SF peaks as shown in Fig. 2. Peak I $\left(\lambda_{\text {syn }} \approx 290-305 \mathrm{~nm}\right)$ has a relatively low intensity. Peak II $\left(\lambda_{\text {syn }} \approx 340-360 \mathrm{~nm}\right)$ and peak IV $\left(\lambda_{\text {syn }} \approx 460\right.$ $480 \mathrm{~nm}$ ) have moderate intensities. The intensity of Peak III $\left(\lambda_{\text {syn }} \approx 380-420 \mathrm{~nm}\right)$ is always the strongest one. As compared with the EEM spectra, it is seen that peak I is located in the shoulder ranges of tryptophan-like fluorophores. It is assigned to the aromatic amino acids of tryptophan- and phenylalanine-like, to the proteins containing these aromatic amino acids (Yamashita and Tanoue, 2003; Stedmon et al., 2003). Peak II is located in the shoulder range of humic-like fluorophores. The counterparts of peak III and peak IV cannot be found on the EEM spectra. According to Smith and Kramer (1999), the components exhibiting peak III have polycyclic aromatic structures like flavone and coumarine (with ex/em of 400-420/460 $480 \mathrm{~nm}$ ). Peak IV is probably attributed to the polycyclic aromatic structures with more aromatic rings and a higher degree of conjugation (Chen et al., 2003). Therefore, the SF spectra reveal for all the original DOM fractions the existence of protein-like constituents and highly polycyclic aromatic materials, which are hard to be discerned from the EEM spectra.

Ozonation always reduces substantially the intensity of peaks II, III, and IV for all examined DOM fractions indicating the significant destruction of aromatic structures associated with the generation of carbohydrates. The peak assigned to protein-like for HON and HIB is decreased to some extent, while that for HOA and HIA is enhanced. 

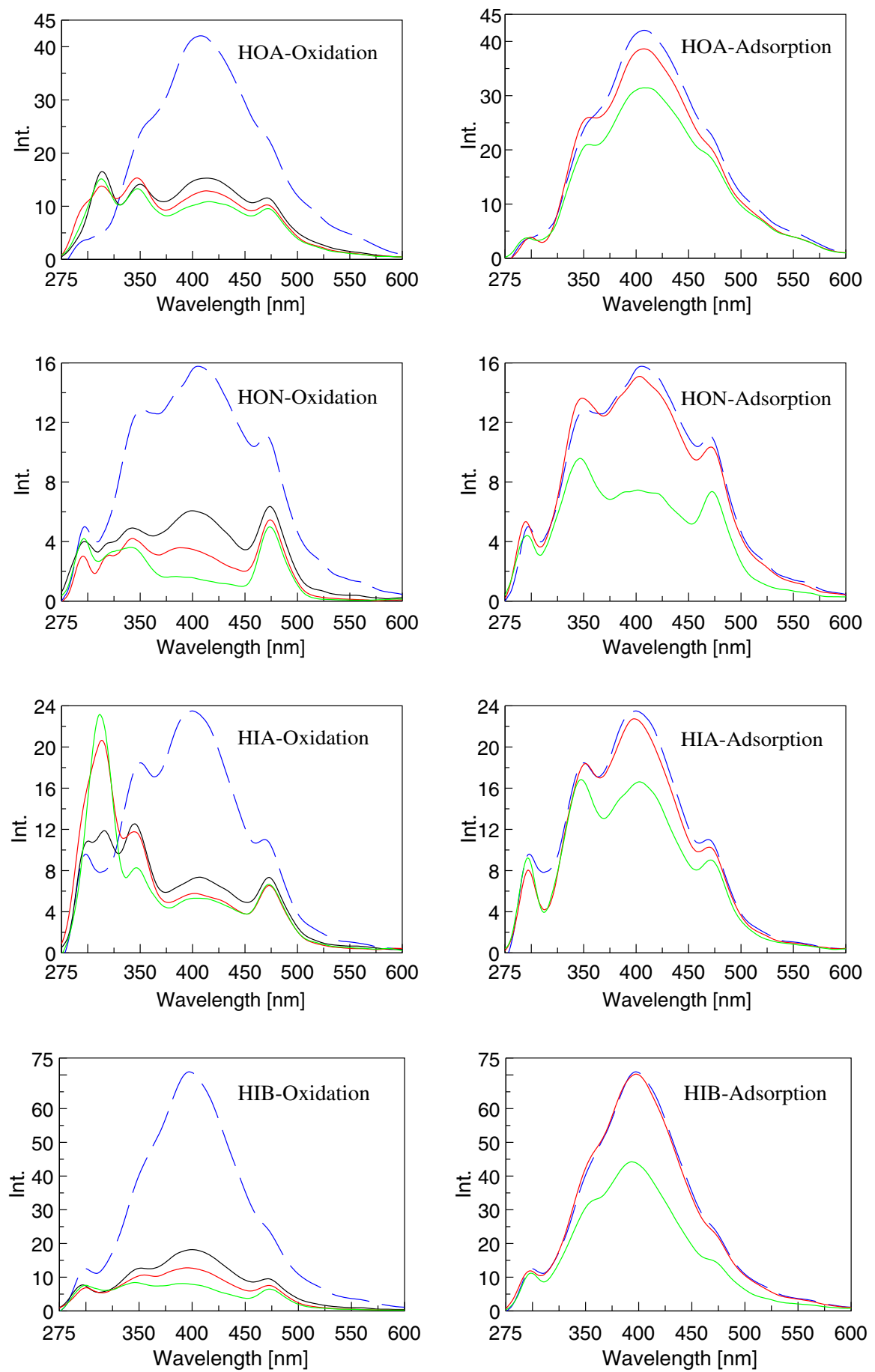

Fig. 2. Synchronous ( $66 \mathrm{~nm}$ offset) fluorescence spectra of the DOM fractions. Blue dashed lines: original fractions; black lines: ozonation alone; red lines: FeOOH catalytic ozonation (left) and adsorption (right); green lines: $\mathrm{CeO}_{2}$ catalytic ozonation (left) and adsorption (right). (For interpretation of the references to colour in this figure legend, the reader is referred to the web version of this article.)

A new peak centered at $315 \mathrm{~nm}$, emerges in ozonation of HOA and HIA with a relatively high intensity. It can be ascribed to the emergence and enrichment of the compounds with low aromaticity and low molecular weight during ozonation of HOA and HIA. The new peak is not found for ozonation of $\mathrm{HON}$ and HIB.

In comparison to ozonation, $\mathrm{O}_{3} / \mathrm{FeOOH}$ oxidation reduces further the intensities of all the peaks of $\mathrm{HON}$ and HIB. Peaks III and IV of HOA and peaks II, III, and IV of HIA are also decreased further by $\mathrm{O}_{3} / \mathrm{FeOOH}$ oxidation. The $\mathrm{O}_{3} / \mathrm{FeOOH}$ oxidation-induced intensity changes of other peaks of HOA and HIA are more complex compared to the ozonation-induced changes. The intensities of Peak I of both HOA and HIA and Peak II of HOA increase slightly. As the new peak at $315 \mathrm{~nm}$ is concerned, $\mathrm{O}_{3} / \mathrm{FeO}-$ $\mathrm{OH}$ significantly enhances its intensity for HIA and slightly 
reduces its intensity for HOA. The results indicate that $\mathrm{O}_{3} /$ $\mathrm{FeOOH}$ oxidation can enhance the destruction of almost all fluorophores of HON and HIB. The destruction of polycyclic aromatic structure of HIA and the highly condensed aromatic structure of $\mathrm{HOA}$ is also improved by $\mathrm{O}_{3} / \mathrm{FeOOH}$ oxidation. It also promotes the enrichment of low aromatic structures for HIA and exposes more protein-like functionalities for HOA and HIA.

In comparison to ozonation, $\mathrm{O}_{3} / \mathrm{CeO}_{2}$ oxidation reduces further the intensities of peaks II, III, and IV for the DOM fractions. As the new peak at $315 \mathrm{~nm}$ is concerned, $\mathrm{O}_{3} /$ $\mathrm{CeO}_{2}$ oxidation slightly reduces its intensity for $\mathrm{HOA}$ and significantly enhances its intensity for HIA compared with ozonation alone. The impact of $\mathrm{O}_{3} / \mathrm{CeO}_{2}$ oxidation on peak I of HON and HIB is similar with that of ozonation, while its impact on peak I of HOA and HIA is difficult to discern because this peak is overlaid by the new peak at $315 \mathrm{~nm}$.

It is noted that $\mathrm{FeOOH}$-adsorption reduces very slightly the intensities of the peaks of the individual DOM fractions. $\mathrm{CeO}_{2}$-adsorption substantially reduces the intensities of peaks II, III, and IV of these fractions, indicating that $\mathrm{CeO}_{2}$ preferentially adsorbs polycyclic aromatic DOM components. Since $\mathrm{O}_{3} / \mathrm{CeO}_{2}$ is more efficient to reduce the intensities of these fluorophores than ozonation and $\mathrm{O}_{3} / \mathrm{FeOOH}$, the results indicate that the adsorption of these fluorophores on the catalyst surface is important to improve the reduction of these fluorophores' intensities in catalytic ozonation, which was also mentioned by Uyguner and Bekbolet (2005) in DOM oxidation by $\mathrm{UV} / \mathrm{TiO}_{2}$. The contribution of adsorption to the improved intensity reduction is possibly ascribed to: (1) surface concentration and/ or complexation of the fluorophores, which promotes the ozonation of them on the catalyst surfaces; and (2) adsorption of the fluorophores which is left after oxidation.

\section{Conclusions}

The EEM spectra reveal that ozonation substantially reduces the aromaticity of humic-like structures and enriches electron withdrawing groups for the examined DOM fractions. Possibly due to its ability in promoting hydroxyl radical generation from aqueous ozone, $\mathrm{FeOOH}$ significantly improves the decomposition of the humic-like structures, although the adsorption of them on the surface of the catalyst is relatively insignificant. Owing to the much stronger surface binding ability of $\mathrm{CeO}_{2}$ for the DOM fractions, $\mathrm{O}_{3} / \mathrm{CeO}_{2}$ improves notably the removal efficiency of the humic-like structures.

The synchronous spectra reveal for the original DOM fractions the existence of protein-like functionalities and highly polycyclic aromatic structures besides the humiclike. The synchronous spectra indicate that ozonation of HIA and HOA yields a significant amount of by-products with low aromaticity and low molecular weight. Catalytic ozonation enhances substantially the formation of these products from HIA. Catalytic ozonation also improves the oxidation of highly polycyclic aromatic structures for all the examined fractions compared to ozonation alone.

The EEM spectra combined with the synchronous spectra indicate that ozonation of HIA and HOA increases the intensity of protein-like fluorophores. It is possibly due to the break down of high-molecule proteinaceous material while exposing low-molecule aromatic amino functionalities. At normal ozone dosage, $\mathrm{pH}$, and reaction time, catalytic ozonation with $\mathrm{FeOOH}$ and $\mathrm{CeO}_{2}$ inhibit the enrichment of the protein-like fluorophores for HOA. For HIA, the enrichment of tryptophan-like functionalities is enhanced by the catalysts, while that of tyrosine-like is enhanced by $\mathrm{FeOOH}$, but slightly inhibited by $\mathrm{CeO}_{2}$.

\section{Acknowledgment}

The authors greatly appreciate the National Natural Science Foundation of China for its financial support to this work (Project No. 50578051).

\section{References}

Alberts, J.J., Takács, M., 2004. Comparison of the natural fluorescence distribution among size fractions of terrestrial fulvic and humic acids and aquatic natural organic matter. Org. Geochem. 35, 1141-1149.

Baker, A., 2002. Fluorescence excitation-emission matrix characterization of river waters impacted by a tissue mill effluent. Environ. Sci. Technol. 36, 1377-1382.

Cabaniss, S.E., 1992. Synchronous fluorescence spectra of metal-fulvic acid complexes. Environ. Sci. Technol. 26, 1133-1139.

Chen, J., LeBoeuf, E.J., Dai, S., Gu, B., 2003. Fluorescence spectroscopic studies of natural organic matter fractions. Chemosphere 50, 639-647.

Coble, P.G., 1996. Characterization of marine and terrestrial DOM in seawater using excitation-emission matrix spectroscopy. Mar. Chem. 51, 325-346.

Elliott, S., Lead, J.R., Baker, A., 2006. Characterisation of the fluorescence from freshwater, planktonic bacteria. Water Res. 40, 2075-2083.

Gracia, R., Cortes, S., Sarasa, J., Ormad, P., Ovelleiro, J.L., 2000. TiO $2^{-}$ catalysed ozonation of raw Ebro river water. Water Res. 34, 1525 1532.

Griffini, O., Bao, M.L., Barbieri, K., Burrini, D., Santianni, D., Pantani, F., 1999. Formation and removal of biodegradable ozonation byproducts during ozonation-biofiltration treatment: pilot scale evaluation. Ozone Sci. Eng. 21, 79-98.

Her, N., Amy, G., McKnight, D., Sohn, J., Yoon, Y., 2003. Characterization of DOM as a function of MW by fluorescence EEM and HPLC-SEC using UVA, DOC, and fluorescence detection. Water Res. 37, 4295-4303.

Kandori, K., Fukuoka, M., Ishikawa, T., 1991. Effects of citrate ion on the formation of ferric oxide hydroxide particles. J. Mater. Sci. 26, 3313-3319.

Kasprzyk-Hordern, B., Ziólek, M., Nawrocki, J., 2003. Catalytic ozonation and methods of enhancing molecular ozone reactions in water treatment. Appl. Catal. B Environ. 46, 639-669.

Kasprzyk-Hordern, B., Raczyk-Stanisławiak, U., Świetlik, J., Nawrocki, J., 2006. Catalytic ozonation of natural organic matter on alumina. Appl. Catal. B Environ. 62, 345-358.

Korshin, G.V., Benjamin, M.M., Sletten, R.S., 1997. Adsorption of natural organic matter (NOM) on iron oxide: effects on NOM composition and formation of organo-halide compounds during chlorination. Water Res. 31, 1643-1650.

Korshin, G.V., Kumke, M.U., Li, C.W., Frimmel, F.H., 1999. Influence of chlorination on chromophores and fluorophores in humic substances. Environ. Sci. Technol. 33, 1207-1212. 
Laiti, E., Öhman, L.O., Nordin, J., Sjöberg, S., 1995. Acid/base properties and phenylphosphonic acid complexation at the aaged $\gamma-\mathrm{Al}_{2} \mathrm{O}_{3} /$ water interface. J. Colloid Interf. Sci. 175, 230-238.

Lee, J.E., Jin, B.S., Cho, S.H., Han, S.H., Joo, O.S., Jung, K.D., 2005. Catalytic ozonation of humic acids with $\mathrm{Fe} / \mathrm{MgO}$. React. Kinet. Catal. Lett. 85, 65-71.

Leenheer, J.A., 1981. Comprehensive approach to preparative isolation and fractionation of dissolved organic carbon from natural waters and wastewaters. Environ. Sci. Technol. 15, 578-587.

Lim, H.N., Choi, H., Hwang, T.M., Kang, J.W., 2001. Characterization of ozone decomposition in a soil slurry: kinetics and mechanism. Water Res. 36, 219-229.

Liu, R., Lead, J.R., Baker, A., 2007. Fluorescence characterization of cross flow ultrafiltration derived freshwater colloidal and dissolved organic matter. Chemosphere 68, 1304-1311.

Ma, J., Graham, N.J.D., 2000. Degradation of atrazine by manganesecatalyzed ozonation: influence of radical scavengers. Water Res. 34, 3822-3828.

McKnight, D.M., Boyer, E.W., Westerhoff, P.K., Doran, P.T., Kulbe, T., Andersen, D.T., 2001. Spectrofluorometric characterization of dissolved organic matter for indication of precursor organic material and aromaticity. Limnol. Oceanogr. 46, 38-48.

Mobed, J.J., Hemmingsen, S.L., Autry, J.L., McGown, L.B., 1996. Fluorescence characterization of IHSS humic substances: total luminescence spectra with absorbance correction. Environ. Sci. Technol. 30, 3061-3065

Newcombe, G., Hayes, R., Drikas, M., 1993. Granular activated carbon: importance of surface properties in the adsorption of naturally occurring organics. Colloid Surf. A 78, 65-71.

Park, J.S., Choi, H., Ahn, K.H., Kang, J.W., 2004. Removal mechanism of natural organic matter and organic acid by ozone in the presence of goethite. Ozone Sci. Eng. 26, 141-151.

Peuravuori, J., Koivikko, R., Pihlaja, K., 2002. Characterization, differentiation and classification of aquatic humic matter separated with different sorbents: synchronous scanning fluorescence spectroscopy. Water Res. 36, 4552-4562.

Sierra, M.M.D., Giovanela, M., Parlanti, E., Soriano-Sierra, E.J., 2005. Fluorescence fingerprint of fulvic and humic acids from varied origins as viewed by single-scan and excitation/emission matrix techniques. Chemosphere 58, 715-733

Singer, P.C., 1999. Humic substances as precursors for potentially harmful disinfection by-products. Water Sci. Technol. 40 (9), 25-30.

Smith, D.S., Kramer, J.R., 1999. Fluorescence analysis for multi-site aluminum binding to natural organic matter. Environ. Int. 25, 295-306.

Stedmon, C.S., Markager, S., Bro, R., 2003. Tracing dissolved organic matter in aquatic environments using a new approach to fluorescence spectroscopy. Mar. Chem. 82, 239-254.

Stumm, W., 1992. Chemistry of the Solid-Water Interface. John Wiley and Sons, New York, pp. 15-20.

Świetlik, J., Dabrowska, A., Raczyk-Stanislawiak, U., Nawrocki, J., 2004. Reactivity of natural organic matter fractions with chlorine dioxide and ozone. Water Res. 38, 547-558.

Świetlik, J., Sikorska, E., 2004. Application of fluorescence spectroscopy in the studies of natural organic matter fractions reactivity with chlorine dioxide and ozone. Water Res. 38, 3791-3799.

Tombácz, E., Libor, Z., Illés, E., Majzik, A., Klumpp, E., 2004. The role of reactive surface sites and complexation by humic acids in the interaction of clay mineral and iron oxide particles. Org. Geochem. 35, 257-267.

Uyguner, C.S., Bekbolet, M., 2005. Evaluation of humic acid photocatalytic degradation by UV-vis and fluorescence spectroscopy. Catal. Today 101, 267-274.

Vo-Dinh, T., 1978. Multicomponent analysis by synchronous luminescence spectrometry. Anal. Chem. 50, 396-401.

Win, Y.Y., Kumke, M.U., Specht, C.H., Schindelin, A.J., Kolliopoulos, G., Ohlenbush, G., Kleiser, G., Hesse, S., Frimmel, F.H., 2000. Influence of oxidation of dissolved organic matter on subsequent water treatment processes. Water Res. 34, 2098-2104.

Yamashita, Y., Tanoue, E., 2003. Chemical characterization of proteinlike fluorophores in DOM in relation to aromatic amino acids. Mar. Chem. 82, 255-271.

Yost, E.C., Tejedor-Tejedor, M.I., Andersonn, M.A., 1990. In situ CIRFTIR characterization of salicylate complexes at the goethite/aqueous solution interface. Environ. Sci. Technol. 24, 822-828.

Zhang, T., Ma, J., Chen, Z., Qi, H., Guo, J., 2005. Effect of organic acids adsorption on catalytic ozonation with metal oxides (in Chinese). Environ. Sci. 26 (5), 85-89. 